\title{
Improving glaucoma filtering surgery
}

Since 1857, which saw the birth of successful glaucoma surgery with von Graefe's iridectomy, many procedures have come and gone but only a few have stood the test of time. Cairns' 'guarded sclerostomy'

(trabeculectomy) ${ }^{1}$ is one such operation. It replaced full-thickness filtering procedures to become the procedure of choice because, having first proved to be equally successful in lowering intraocular pressure (IOP), its superiority lay in the fact it was a safer operation with relatively fewer risks of complications.

This continuing quest for safer glaucoma surgery is what has recently motivated surgeons to revist non-penetrating trabecular surgery. It was first described almost 30 years ago with the aim of avoiding the potential complications associated with ocular entry. ${ }^{2}$ Following more recent modifications it has been promoted as a serious alternative to trabeculectomy, largely for its more attractive complication profile. ${ }^{3,4}$ However, with increasing recognition that IOPs in the low teens are required to prevent or minimise glaucoma progression, ${ }^{5,6}$ the degree of long-term IOP control achieved by a new technique should be the primary measure by which it is judged and which ultimately determines its place in the management of glaucoma. Furthermore, any procedure which now desires the 'gold standard of treatment' title must challenge for it in the ring of prospective, randomised controlled trials. Complication profile aside, it must prove to have at least the same degree of efficacy as the procedure it intends to replace before it can be considered a serious contender.

The results of some of these prospective, randomised studies are now becoming available to suggest that the short-term gain of a lower rate of complications seen with non-penetrating deep sclerectomy (NPDS) is at the expense of long-term benerit in the form of adequate IOP control. The study by Chiselita in this issue ${ }^{7}$ compares NPDS without adjunctive implant to trabeculectomy, with no post-operative use of antimetabolites in patients with primary open angle glaucoma. He reports statistically significant lower IOP in the trabeculectomy group throughout the study along with a greater degree of IOP reduction following trabeculectomy $(35.7 \%)$ as compared with NPDS (25.1\%) at 18 months. When success was defined in terms of IOP $<21 \mathrm{mmHg}$ without medications, survival analysis demonstrated 93\% attained this in the trabeculectomy group as opposed to $45 \%$ in the NPDS group at 18 months. However, trabeculectomy was associated with more early post-operative complications in the form of hyphaema and a greater need for subsequent cataract surgery. These findings are similar to those of Gandolfi and Cimino $^{8}$ and even to those of Carassa ${ }^{9}$ who compared trabeculectomy with viscocanulostomy but with a shorter follow-up. However, recently published results by El Sayyad et al. ${ }^{10}$ comparing trabeculectomy and NPDS without adjunctive implant, instead suggest a comparable final IOP and mean IOP reduction. But, in contrast to Chiselita's study, these results were achieved with goniopuncture in $10 \%$ of the NPDS group and 5-fluorouracil injections. Interestingly, El Sayyad et al. ${ }^{10} \mathrm{did}$ not detect a significant difference in the rate of complications.

Studies such as Chiselita's should be commended not only for giving us a perspective as to where NPDS fits in our surgical armamentarium, but also for highlighting the fact that our current gold standard is far from ideal. So, while we encourage the development of effective, safer operations we should continue to 'fine-tune' a time-proven technique to achieve both satisfactory IOP control and a lower rate of complications. With regard to the prevention of complications, most of our attention has focused on dealing with those that occur in the early post-operative period. For example, the introduction of post-operative scleral flap suture release has been a major advance in terms of the prevention of early hypotony. However, bleb morphology and its role in late complications, such as bleb leaks and infection, has been largely ignored despite its known relationship to wound construction. Yet by encouraging posterior, unrestricted drainage of aqueous with the use of a fornix-based conjunctival flap, ${ }^{11,12}$ an increase in antimetabolite treatment area $^{13}$ and a large flap with suturing that promotes posterior rather than lateral flow, it may be possible to achieve the much desired diffuse, non-cystic bleb. ${ }^{14}$

No operation is immune to complications and Cairns' trabeculectomy, the gold standard of glaucoma surgery, is no exception. Our response to this can be threefold: we can (i) develop techniques that manage the
M. Papadopoulos

P.T. Khaw

Glaucoma Unit and Wound Healing Research Unit Moorfields Eye Hospital and Institute of Ophthalmology London, UK

Miss M. Papadopoulos Glaucoma Unit Institute of Ophthalmology Bath Street London EC1V 9EL, UK

We would like to acknowledge the support of the Medical Research Council, grant G9330070 
complications, (ii) attempt to prevent them by modifying the technique and/or (iii) develop a safer operation which does not sacrifice efficacy. In fact, we should continue to explore all these challenging avenues in the hope of improving both the efficacy and the safety of glaucoma filtering surgery. However, we should bear in mind that 'if one procedure replaces another, it must be significantly better than its predecessor' ${ }^{15}$

\section{References}

1. Cairns JE. Trabeculectomy: preliminary report of a new method. Am J Ophthalmol 1968;66:673-9.

2. Krasnov MM. Sinusotomiia pri glaukome. Vestn Oftal 1963;77:37-41.

3. Zimmerman TJ, Kooner KS, et al. Trabeculectomy vs nonpenetrating trabeculectomy: a retrospective study of two procedures in phakic patients with glaucoma. Ophthalmic Surg 1984;15:734-40.

4. Mermoud A, Schnyder CC, Sickenberg M, Chiou AGY, Hediguer SEA, Faggioni R. Comparison of deep sclerectomy with collagen implant and trabeculectomy in open angle glaucoma. J Cataract Refract Surg 1999;25:323-31.

5. Migdal C, Gregory W, Hitchings R. Long-term functional outcome after early surgery compared with laser and medicine in open-angle glaucoma. Ophthalmology 1994;101:1651-7.

6. The Advanced Glaucoma Intervention Study (AGIS 7). The relationship between control of intraocular pressure and visual field deterioration. Am J Ophthalmol 2000;130:429-40.
7. Chiselita D. Non-penetrating deep sclerectomy versus trabeculectomy in primary open angle glaucoma surgery. Eye 2001;15:197-201.

8. Gandolfi SA, Cimino L. Deep sclerectomy without absorbable implants and with unsutured scleral flap: prospective, randomised 2-year clinical trial vs trabeculectomy with releasable sutures. Invest Ophthalmol Vis Sci 2000;41:S83.

9. Carassa RG. Viscocanalostomy. In: Weinreb RN, Leibmann JM, editors. Glaucoma 1999: concepts and controversies. American Academy of Ophthalmology, 1999:113-20

10. El-Sayyad F, Helal M, El-Kholify H, Khalil M, El-Maghraby A. Nonpenetrating deep sclerectomy versus trabeculectomy in bilateral primary open angle glaucoma. Ophthalmology 2000;107:1671-4.

11. Katz LJ, Costa VP, Spaeth GL. Filtration surgery. In: Ritch R, Shields MB, Krupin T, editors. The glaucomas. St Louis: CV Mosby, 1996:1661-702.

12. El Sayyad F, El Rashood A, Helal M, Hisham M, El Maghraby A. Fornix-based versus limbal-based conjunctival flaps in initial trabeculectomy with postoperative 5-fluorouracil: four-year follow-up findings. J Glaucoma 1991;8:124-8.

13. Cordeiro MF, Constable PH, Alexander RA, Bhattacharya SS, Khaw PT. Effect of varying the mitomycin-C treatment area in glaucoma filtration surgery in the rabbit. Invest Ophthalmol Vis Sci 1997;38:1639-46.

14. Wells AP, Cordeiro MF, Bunce CV, Khaw PT. Cystic bleb related complications in limbus versus fornix based flaps in paediatric and young adult trabeculectomy with high dose mitomycin C. Invest Ophthalmol Vis Sci 2001 (Suppl); in press.

15. Watson PG. Surgery of the glaucomas. Br J Ophthalmol 1972;56:299-306 